\title{
Diagnóstico bacteriológico, citológico e histopatológico da endometrite equina
}

\section{Bacteriological, cytological and histopathological diagnosis of equine endometritis}

Carla Fernanda Paranhos de Moura Carvalho, ${ }^{*}$ Hélcio Resende Borba, ${ }^{\star *}$ José Antônio Silva Ribas, ${ }^{* \star *}$ Rosana Rocha Barros ${ }^{* * * *}$

\begin{abstract}
Resumo
A endometrite é uma das principais causas de infertilidade equina, com considerável impacto econômico. Porém, não existe consenso sobre o método ideal de diagnóstico. O objetivo deste estudo foi avaliar os achados bacteriológicos, citológicos e histopatológicos de 21 éguas com histórico de infertilidade. Escherichia coli (10 cepas), estreptococos do grupo C [(EGC), Streptococcus equi subsp. zooepidemicus (4) e Streptococcus dysgalactiae subsp. equisimilis (3)], Enterococcus sp. (3) e Staphylococcus aureus (2) foram isolados de secreção uterina de 13 animais. Em oito animais foram isoladas espécies não patogênicas. Resistência à cefalotina, clindamicina, eritromicina, penicilina e tetraciclina foi observada entre as espécies. Esfregaços contendo células da parede uterina foram classificados quanto ao grau de inflamação em leve (6), moderada ou intensa (12) e ausência de inflamação (3). Infiltrados celulares foram observados em todos os fragmentos de biópsia, com grau de intensidade variando entre moderado e intenso. $O$ isolamento de $E$. coli foi significativamente associado à inflamação intensa, enquanto a presença de espécies não patogênicas foi significativamente relacionada com a ausência de processo inflamatório.
\end{abstract}

Palavras-chave: cultura bacteriana, análise citológica, Escherichia coli, égua, endometrite.

\begin{abstract}
Endometritis is one of the major causes of equine infertility, with considerable economic impact. However, there is no agreement for the ideal method of diagnosis. The objective of this study was to evaluate bacteriological, cytological and histopathological findings of 21 mares with infertility history. Escherichia coli (10 strains), Group C Streptococcus [(GCS), Streptococcus equi subsp. zooepidemicus (4) and Streptococcus dysgalactiae subsp. equisimilis (3)], Enterococcus sp. (3) and Staphylococcus aureus (2) were isolated from 13 animals. Non-pathogenic organisms were recovered from eight animals. Resistance to cephalothin, clindamycin, erythromycin, penicillin and tetracycline was observed among species. Smears containing cells of the uterine wall were classified according to inflammation degree in mild (6), moderate or severe (12) and absence of inflammation (3). Cellular infiltrates were observed in all biopsy samples analyzed, with a degree of intensity ranging from moderate to intense. The presence of $E$. coli was significantly related to severe inflammation, while non pathogenic organisms were significantly related to absence ou mild inflammation.
\end{abstract}

Keywords: bacteriological culture, cytological analysis, Escherichia coli, mare, endometritis.

\section{Introdução}

A endometrite bacteriana representa uma das principais causas de infertilidade em éguas. Em geral, a susceptibilidade do animal à infecção é associada à idade avançada e a múltiplos partos (McKinnon e Voss, 1993). A ação dos micro-organismos que penetram no útero pela cérvix após cobertura ou parição resulta em endometrites ou metrites, o que diminui de forma considerável as chances de uma gestação a termo e acarreta prejuízos (Ricketts, 1981; Gastal et al., 1989). Estas infecções são frequentemente causadas por micro-organismos oportunistas (Ricketts et al., 1993), com destaque para Escherichia coli, estreptococos do grupo C (EGC), em especial Streptococcus equi subsp. zooepidemicus, Staphylococcus aureus e Rhodococcus equi.

\footnotetext{
* Instituto de Veterinária, Universidade Federal Rural do Rio de Janeiro. Br 467, Km 7. Seropédica, RJ. 23890-000.

carla_mouracarvalho@hotmail.com. Endereço atual: Universidade Severino Sombra. Av Expedicionário Oswaldo de Almeida Ramos, 280, Centro, Vassouras, RJ. 27700-000

** Instituto de Biologia, Universidade Federal Rural do Rio de Janeiro. Br 467, Km 7. Seropédica, RJ. 23890-000. borba@ufrrj.br

*** Instituto Biomédico, Universidade Federal Fluminense. Rua Prof. Hernani de Melo 101, Niterói, RJ. 24210-130. ribasjas@uol.com.br

**** Instituto Biomédico, Universidade Federal Fluminense. Rua Prof. Hernani de Melo 101, Niterói, RJ. 24210-130. miprosana@vm.uff.br. Autor para correspondência.
} 
Outras espécies relatadas são Klebsiella pneumoniae e Pseudomonas aeruginosa (Langoni et al., 1994). Bactérias anaeróbias como Bacteroides fragilis são associadas à infecção principalmente em éguas no período pós-parto e no cio do potro (Ricketts e MacKintosh, 1987).

Dentre os métodos de diagnóstico laboratorial, a cultura bacteriana de secreção do endométrio, utilizando-se swabs protegidos tem sido utilizada na detecção do agente etiológico (Nielsen, 2005). O estudo citológico do material coletado com o auxílio de swabs ou flushes tem sido recomendado para avaliar o ambiente uterino, uma vez que a presença de neutrófilos no lúmen é um importante indicador de inflamação (Asbury et al., 1984; Causey, 2006). A biópsia endometrial é um procedimento confiável e seguro para 0 diagnóstico e prognóstico de distúrbios relacionados com a infertilidade equina (Schoon et al., 1997; Keller et al., 2004). A ocorrência de infiltração celular é avaliada de acordo com o tipo de célula, distribuição e intensidade.

O tratamento da endometrite deve iniciar-se com a eliminação das causas predisponentes e a utilização de lavagens e infusão de antimicrobianos, sendo ideal a identificação do micro-organismo e a realização do antibiograma (Jacob et al., 2002). Considerando as principais espécies envolvidas na infecção, estudos nacionais apontam níveis variados de resistência aos antimicrobianos, com predomínio de susceptibilidade aos beta-lactâmicos entre $S$. equi subsp. zooepidemicus e aos aminoglicosídeos entre E. coli (Langoni et al., 1994; Silva et al., 1999; Aguiar et al., 2005).

Apesar da identificação de éguas susceptíveis ser de extrema importância para o tratamento e obtenção da prenhez, o reconhecimento destes animais é um problema na rotina clínica, uma vez que não existe um consenso sobre o método ideal de diagnóstico de endometrite. O objetivo deste estudo foi avaliar a utilização de diferentes métodos laboratoriais (cultura bacteriana e análises citológica e histopatológica) para o diagnóstico de endometrite, em éguas com histórico de infertilidade e outros sinais clínicos da doença, visando assim gerar informações que possam contribuir para a maior acurácia no diagnóstico.

\section{Material e métodos}

\section{Histórico e exame clínicos}

De setembro de 2005 a novembro de 2007, foram selecionadas, de um total de 135 animais avaliados, 21 éguas com idades entre 8 e 30 anos e raças variadas, de propriedades particulares no estado do Rio de Janeiro e do Instituto de Zootecnia da UFRRJ. Como fatores de inclusão considerouse o histórico reprodutivo do animal (idade, número de gestações, ocorrência de abortamento, parto distócico, endometrite recorrente e ausência de prenhez em uma ou mais estações de monta) e o exame clínico (inspeção do aparelho genital por meio de palpação retal e exame ultrassonográfico). Após o exame clínico procedeu-se à coleta de amostras para as análises bacteriológicas, citológicas e histopatológicas.

\section{Cultura bacteriológica}

Swabs estéreis protegidos foram introduzidos no corpo uterino, removidos e acondicionados em tubos contendo caldo BHI (Merck, Rio de Janeiro, RJ). Após incubação em atmosfera ambiente a $37^{\circ} \mathrm{C}$ por $18-24$ horas, cada amostra foi semeada nos meios de cultura agar sangue (AS), agar manitol salgado (MS) e agar Teague (Difco - BD, Sparks, MD, EUA) e mantidas sob as mesmas condições de incubação por 18-24 horas. A partir do crescimento bacteriano procedeuse à identificação das espécies de acordo com Murray et al. (1999) e Facklam (2002).

\section{Teste de susceptibilidade a antimicrobianos}

As cepas de Enterococcus sp., E. coli, S. aureus e EGC ( $S$. dysgalactiae subsp. equisimilis e $S$. equi subsp. zooepidemicus) foram submetidas ao teste de susceptibilidade aos antimicrobianos pelo método de difusão em agar, de acordo com as recomendações do CLSI (2009). Os seguintes antimicrobianos foram utilizados: penicilina G $10 \mathrm{U}$ e vancomicina $30 \mu \mathrm{g}$ (Enterococcus sp); ampicilina $10 \mu \mathrm{g}$, cefalotina $30 \mu \mathrm{g}$ e gentamicina $10 \mu \mathrm{g}(E$. coli); oxacilina $1 \mu \mathrm{g}$ e penicilina $\mathrm{G} 10 \mathrm{U}$ ( $S$. aureus); clindamicina $2 \mu \mathrm{g}$, eritromicina $15 \mu \mathrm{g}$, penicilina G $10 \mathrm{U}$ e tetraciclina $30 \mu \mathrm{g}$ (EGC) (Cecon, São Paulo, SP). A leitura e interpretação dos resultados foram feitas de acordo com as recomendações do CLSI (2009).

\section{Avaliação citológica}

Os esfregaços foram confeccionados a partir do material coletado com auxílio de um swab estéril, colocando-o em contato com a parede uterina e realizando movimentos de rotação por 15 segundos. Após a coleta, o material foi imediatamente fixado e submetido à coloração com Panótico. A análise foi realizada por microscopia óptica, quantificandose o número relativo de neutrófilos, macrófagos, eosinófilos e outras células inflamatórias. Os esfregaços foram classificados quanto ao grau de inflamação em leve (1-2 neutrófilos por campo), moderada (3-5 neutrófilos por campo) e intensa ( $>5$ neutrófilos por campo).

\section{Avaliação Histopatológica}

A pinça de biópsia foi introduzida na vagina e foi retirado um fragmento da porção do corpo uterino. As amostras foram acondicionadas em solução de formol a $10 \%$ e submetidas à metodologia padronizada de processamento (Ricketts, 1975; Kenney, 1978). Por microscopia óptica, avaliou-se o número de camadas, formato das células e presença de células inflamatórias no epitélio luminal, presença de células inflamatórias nos estratos compacto e esponjoso, e ocorrência de perivasculite nos vasos. O grau de alteração histológica foi avaliado segundo Kenney e Doig (1986), que classifica a ocorrência de infiltração em quatro categorias (I, Ila, Ilb e III), modificado por Schoon et al. (1992).

\section{Análise estatística}

Foi empregado o teste exato de Fisher. Valor de $p<0,05$ foi considerado estatisticamente significativo.

\section{Resultados}

O exame clínico demonstrou a presença de líquido no ambiente uterino em $38,1 \%$ das éguas e $42,8 \%$ apresentavam pneumovagina. Escherichia coli (10 cepas), Streptococcus equi subsp. zooepidemicus (4 cepas), Streptococcus dysgalactiae subsp. equisimilis (3 cepas), 
Enterococcus sp. (3 cepas) e Staphylococcus aureus (2 cepas) foram isolados de amostras uterinas oriundas de 13 animais $(61,9 \%)$, com crescimento concomitante de duas espécies em nove amostras. Isolou-se E. coli em $88,9 \%$ dos animais que apresentavam pneumovagina. Estafilococos coagulase negativos, micrococos e bastonetes Gram-positivos foram relacionados como organismos não patogênicos. Resistência intermediária à cefalotina foi detectada em $60 \%$ das cepas de E. coli. Entre EGC observou-se resistência à eritromicina em $25 \%$ das cepas de $S$. equi subsp. zooepidemicus; resistência equi subsp. zooepidemicus e em $66,7 \%$ de $S$. dysgalactiae subsp. equisimilis e à clindamicina em $25 \%$ de $S$. equi subsp. zooepidemicus e em $33,3 \%$ de $S$. dysgalactiae subsp. equisimilis. As duas cepas de Staphylococcus aureus apresentaram resistência à penicilina $\mathrm{G}$.

A avaliação citológica demonstrou a ocorrência de inflamação leve em seis éguas; em duas destas foram isoladas, concomitantemente, cepas de E. coli e Enterococcus sp. e E. coli e EGC. Em apenas um animal foi observado processo inflamatório moderado, sem que houvesse isolamento de micro-organismo relacionado com a endometrite. Em 11 $(52,4 \%)$ éguas foi observada inflamação intensa, e em todos estes animais foram isoladas cepas de $S$. aureus, Enterococcus sp., E. coli e EGC associados ou não entre si. inflamação intensa foi estatisticamente significativa $(p<0,05)$. Por outro lado, o isolamento de organismos não patogênicos foi associado à ausência de processos inflamatórios ou à inflamação leve $(p<0,05)$.

$\mathrm{Na}$ avaliação histopatológica, 38,1\% das éguas foram classificadas como pertencentes ao grupo IIa, 42,9\% ao grupo IIb e $19 \%$ ao grupo III. E. coli, EGC e Enterococcus sp., associados ou não entre si, foram isolados em $61,5 \%$ dos animais que apresentavam as lesões classificadas como IIb e III. Entretanto, lesões IIb e III foram observadas em animais que não apresentavam alterações citológicas ou micro-organismos potencialmente associados à endometrite. Não houve associação estatisticamente significativa entre os resultados obtidos a partir do exame histopatológico e dos demais métodos empregados. A Tabela 1 relaciona os achados bacteriológicos, citológicos e histopatológicos nos animais estudados. plena ou intermediária à tetraciclina em todas as cepas de $S$. $A$ associação entre o isolamento de $E$. coli e ocorrência de

\section{Discussão}

O isolamento de E. coli, EGC e $S$. aureus tem sido observado em estudos realizados em diferentes regiões geográficas, demonstrando que estes micro-organismos são os principais agentes envolvidos na etiologia da endometrite equina (Silva et al., 1999; Ghasemzadeh-Nava et al. 2004; Aguiar et al., 2005), mesmo quando não há alterações inflamatórias significativas (Riddle et al., 2007). Observou-se associação significativa entre $o$ isolamento de $E$. coli e ocorrência de inflamação intensa ( $p$ $<0,05)$. Entretanto, o mesmo não ocorreu quando comparouse EGC e inflamação $(p>0,05)$, provavelmente devido ao número inferior de cepas de EGC.

Ainda que Enterococcus sp. não seja referido como agente de endometrite, uma cepa foi isolada em cultura pura em um animal que apresentava inflamação intensa, sugerindo, neste caso, a participação do gênero na etiologia da infecção.

$\mathrm{O}$ isolamento concomitante de dois patógenos bacterianos ocorreu em $42,8 \%$ dos espécimes analisados e foi associado a intenso processo inflamatório. Este achado está de acordo com o relatado por Riddle et al. (2007), que relacionaram os dados bacteriológicos e citológicos com as taxas de prenhez de 970 éguas. Entre outros resultados, os autores observaram que o isolamento de duas ou mais espécies foi associado à intensa inflamação endometrial.

A análise citológica evidenciou processos inflamatórios, variando de leve a intenso, em $85,7 \%$ dos animais. Esta taxa é elevada quando comparada à observada em outros estudos, como o de Papa et al. (1993), com 47,1\% de inflamação. Estas diferenças provavelmente se devem ao fato de que os animais utilizados no presente estudo apresentavam uma série de fatores característicos de endometrite, tais como idade avançada, ausência de prenhez e pneumovagina, entre outros. Estas características também justificam as alterações histopatológicas observadas em todos os animais, com predomínio dos grupos IIb e III. Estudos anteriores também haviam observado uma correlação entre susceptibilidade à endometrite e a avaliação histopatológica compatível com estes achados (Doig et al., 1981; Keller et al., 2004).

\section{Conclusão}

Tabela 1: Relação entre achados bacteriológicos, citológicos e hitopatológicos a partir dos espécimes uterinos coletados das éguas.

\begin{tabular}{|c|c|c|}
\hline $\begin{array}{l}\text { Espécie isolada } \\
\text { (número de éguas) }\end{array}$ & $\begin{array}{l}\text { Achados citológicos: neutrófilos } \\
\text { p/ campo (número de éguas) }\end{array}$ & $\begin{array}{l}\text { Classificação histopatológica } \\
\text { (número de éguas) }\end{array}$ \\
\hline \multirow[t]{3}{*}{ Microbiota normal (8) } & 0 (3) & Ila (3) \\
\hline & $1-2(4)$ & Ilb (4) \\
\hline & 3-5 (1) & III (1) \\
\hline \multirow{2}{*}{ Escherichia coli (10) } & $1-2(2)$ & Ila (4) \\
\hline & $>5(8)$ & Ilb (3) \\
\hline \multirow{2}{*}{ Streptococcus do grupo C (7) } & $1-2(1)$ & Ila (1) \\
\hline & $>5(6)$ & Ilb (4) \\
\hline Staphylococcus aureus (2) & $>5(2)$ & Illa (2) \\
\hline Enterococcus sp. (3) & $\begin{array}{l}1-2(1) \\
>5(2)\end{array}$ & $\begin{array}{l}\text { Ila (2) } \\
\text { III (1) }\end{array}$ \\
\hline
\end{tabular}

Microbiota normal, isolamento de estafilococos coagulase negativos, estreptococos alfa hemolíticos, bastonetes gram positivos.
$\mathrm{O}$ isolamento de micro-organismos associados à endometrite e a ocorrência de acentuadas alterações citológicas e histopatológicas evidenciou a importância dos três métodos empregados no diagnóstico laboratorial da endometrite equina, ainda que concordância significativa de resultados tenha sido observada apenas entre os métodos bacteriológico e citológico. A acurácia no diagnóstico possibilita um maior êxito na conduta terapêutica, contribuindo para o restabelecimento da taxa de fertilidade destes animais. 


\section{Agradecimentos}

À Pró-Reitoria de Pesquisa, Pós-Graduação e Inovação da Universidade Federal Fluminense (PROPPI-UFF) pelo auxílio financeiro. A Joel Maurício Corrêa da Rosa, professor adjunto do Departamento de Estatística da Universidade Federal Fluminense.

\section{Referências}

AGUIAR, D.M.; RIBEIRO, M.G.;UENO, T.E.; JUNIOR, G.N.; PAES, A.C.; MEGID, J.; LISTONI, F.J.P. Etiologia e sensibilidade in vitro de microorganismos aeróbicos isolados de endometrite equina. Arq. Inst. Biol., v. 72, n. 1, p. 107-109, 2005.

ASBURY, A.C.; GORMAN, N.T.; FOSTER, G.W. Uterine defense mechanisms in the mare: serum opsonins affecting phagocytosis of Streptococcus zooepidemicus by equine neutrophils. Theriogenology, v. 21, n. 2, p. 375-385, 1984.

CAUSEY, R.C.; WEBER, J.A.; EMMANS, E.E.; STEPHENSON, L.A. HOMOLA, A.D. KNAPP, K.R. et al. The equine immune response to Streptococcus equi subspecies zooepidemicus during uterine infection. Vet. Rec., v. 172, p. 248-257, 2006.

CLINICAL LABORATORY STANDARD INSTITUTE. Performance standards for antimicrobial susceptibility testing M100-S19. Clinical Laboratory Standard Institute. Wayne, Pa. 2009.

CLINICAL LABORATORY STANDARD INSTITUTE. Performance standards for antimicrobial disk susceptibility tests; Approved Standard. M02A10. 2009.

DOIG, P. A.; McKNIGHT, J.D.; MILLER, R.B. The use of endometrial biopsy in infertile mare. Can. Vet. J., v. 22, n. 3, p. 72-76, 1981.

FACKLAM, R. What happened to Streptococci: overview of taxonomic and nomenclature changes. Clin. Microbiol. Rev., v. 15, n. 4, p. 613630, 2002.

GASTAL, E.L.; HENRY, M.; NASCIMENTO, F. Influência das alterações uterinas e tubáricas na taxa de fertilização de éguas. Rev. Bras. Reprod. Anim. (Sup.) v. 13, p. 171, 1989.

GHASEMZADEH-NAVA, H.; GHASEMI, F.; TAJIK, P.; SHIRAZI, A. A review of mare endometritis in Iran. J. Eq. Vet. Sci., v. 24, n. 5, p. 188192, 2004.

JACOB, J.C.F.; JESUS, V.L. T.; BARBOSA, H.P.; ZIMMERMAN, M.F., SILVA, A.G.; MELO, C.M. Susceptibilidade antimicrobiana de swab uterino e da fossa clitoriana de éguas com subfertilidade. Rev. Univ. Rural -Série Ciências da Vida (Sup.), v. 22, n. 2, p. 109-114, 2002. KELLER, A.; NEVES, A.P.; AUPPERLE, H.; STEIGER, K.; SCHOON, H.A.; KLUG, E.; GREGORY, R.M.; MATTOS, R.C. Exame histopatológico do endométrio da égua após infecções experimentais repetidas e cinco diferentes tratamentos: aspectos inflamatórios. Acta Sci. Vet., v. 32, n. 3, p. 215-223, 2004.

KENNEY, R.M. Cyclic and pathologic changes of the mare endometrium as detected by biopsy, with a note on early embryonic death. J. Am. Vet. Med. Assoc., v. 172, n. 3, p. 241-262, 1978.
KENNEY, R.M.; DOIG, P.A. Equine endometrial biopsy. In: MORROW D. A. (Ed). Current Therapy in Theriogenology. 2. ed. Philadelphia: W.B. Saunders, p. 723-729, 1986.

LANGONI, H.; ALVARENGA, M.A.; PAPA, F.O.; SAKAMOTO, C.; SIMON, J.J.; LISTONI, F.J.P.; CARREIRA, E. L. C. Estudo microbiológico e citológico do trato genital de éguas. Arq. Bras. Med. Vet. Zootec., v. 46, n. 6, p. 623-636, 1994.

McKINNON, A. O.; VOSS, J. L. (ed.). Equine Reproduction. Blackwell, New Jersey, 1993.

MURRAY. P.;BARON, E. J.; PFALLER, M.; TENOVER, F.; YOLKEN, R. (ed.). Manual of Clinical Microbiology. 7. ed. Washington DC.: American Society for Microbiology, 1999.

NIELSEN, J.M. Endometritis in the mare: A diagnostic study comparing cultures from swab and biopsy. Theriogenology, v. 64, n. 3, p. 510$518,2005$.

PAPA, F.O.; ALVARENGA, M.A.; LANGONI, H.; BONFIM, A.C. Morte embrionária precoce em éguas: Aspectos cito-microbiológicos. $5^{\circ}$ Simpósio Internacional de Reprodução Animal. Portugal. Anais... $5^{\circ}$ Simpósio Internacional de Reprodução Animal, p. 348-353, 1993.

RICKETTS, S.W. The technique and clinical application of endometrial biopsy in the mare. Eq. Vet. J. v. 7, p. 102-108, 1975.

RICKETTS, S.W. Bacteriological examinations of mare's cervix: techniques and interpretation of results. Vet. Rec., v. 108, n. 3, p. 46$51,1981$.

RICKETTS, S.W.; MACKINTOSH, M. E. Role of anaerobic bacteria in equine endometritis. J. Reprod. Fert. (Sup.), v. 35, p. 343-351, 1987.

RICKETTS, S.W.; YOUNG, A.; MEDICI, E.B. Uterine and clitoral cultures. In: MCKINNON A. O.; VOSS, J.L. (Ed). Equine Reproduction. Baltimore: Lea \& Febiger, p. 234-245, 1993.

RIDDLE, W.T.; LEBLANC, M.M.; STROMBERG, A.J. Relationships between uterine culture, cytology and pregnancy rates in a Thoroughbred practice. Theriogenology, v. 68, n. 3, p. 395-402, 2007. SCHOON, H.A.; SCHOON, D.; KLUG, E. Uterusbiopsien als Hilfsmittel $\mathrm{fmr}$ diagnose und prognose von fertilitätsstörungen der stute. Pferdehelikunde, v. 8, p. 355-362, 1992.

SCHOON, H.A.; SCHOON, D.; KLUG, E. Die Endometrium biopsie bei der Stute in Klinisch-gynakologischen Kontext. Pferdeheilkunde, v. 13, p. 453-464, 1997.

SILVA, N.; BRAGA, C.E.; COSTA, G.M.; LOBATO, F.C.F. Isolamento e teste de susceptibilidade a antimicrobianos de bactérias em infecções uterinas de éguas. Arq. Bras. Med. Vet. Zootec., v. 51, n. 3, p. 1-8, 1999. 